\title{
Perinatal Brain Injury
}

National Cancer Institute

\section{Source}

National Cancer Institute. Perinatal Brain Injury. NCI Thesaurus. Code C73501.

Injury to the brain of a newborn infant occurring around the time of birth. 